\title{
Experiences of local residents who portrayed patients in simulated patient exercises
}

\author{
Masako Shomura*1, Haruka Okabe ${ }^{1}$, Satoshi Iwamoto ${ }^{1}$, Futoshi Ohyama ${ }^{1}$, Yoshikazu Kojima ${ }^{2}$ \\ ${ }^{1}$ Faculty of Nursing, School of Medicine, Tokai University, Isehara-shi, Kanagawa, Japan \\ ${ }^{2}$ Department of Nursing, Tokyo University of Information Sciences, Chiba-shi, Chiba, Japan
}

Received: February 15, 2018

DOI: $10.5430 /$ jnep.v8n9p55
Accepted: April 11, 2018

URL: https://doi.org/10.5430/jnep.v8n9p55

\begin{abstract}
With a view toward developing Simulated Patient Exercises (SPE) together with local residents, we aimed to ascertain the role that instructors should play, and the coordination they should undertake to achieve this goal. We interviewed local residents in their 60s and 70s who participated in the participatory SPE program of Tokai University's Adult Nursing Department. We asked the residents about what they gained from, and how they felt about, their experience in the program, and about the kind of support they need to play their role effectively. From the interview data and qualitative inductive analysis, we derived four themes describing the residents' experiences: "Self-encouragement and growth", "hardships as a Simulated Patient", "efforts to improve the training of simulated patients" and "wishes for nursing students". Many of the statements described hardships the residents faced as Simulated Patients, including their nervousness and the burden of learning their role. On the other hand, we also heard many positive statements about how the residents felt encouraged and achieved growth through the experience. For example, in serving as simulated patients, the residents were encouraged by a sense of pride at how they were helping to train nursing students who will in the future help them and their family members, and they felt inspired by the students' earnestness and their cordial learning attitudes, as well as by the camaraderie with fellow Simulated Patients. These positive statements illustrate the value of local residents participating in the program, and they explain why the residents continued to participate.
\end{abstract}

Key Words: Nursing education, Qualitative research, Participatory, Simulated patient, Training exercise

\section{INTRODUCTION}

Healthcare in Japan has grown increasingly sophisticated and complex. Basic nursing courses are now expected to train students to master robust practical nursing skills. To this end, many nursing colleges have innovated their courses, introducing Simulated Patient Exercises ("SPEs") that involve the local community ("participatory SPEs").

H.S. Barrows of McMaster University (Canada) first introduced the participatory SPE approach into Japan in 1975. The participatory SPE approach did not attract much interest at first, but with the growing demand for patient-centered medical practice, medical colleges started training students in communication skills, and they introduced objective structured clinical examination ("OSCE"). Shimizu et al. have enumerated the advantages of participatory SPEs as follows: availability, repeatability, reliability, controllability, adaptability, no risk for patients, reduces student anxiety, feedback from patients, and no time restrictions. ${ }^{[1]}$ On the other hand, the learning outcomes of participatory SPEs vary depending on the efforts of the tutor; moreover, the skills of people who portray the patients also vary. ${ }^{[2]}$ Moreover, meta-analysis shows that SPEs were effective in developing a variety of

\footnotetext{
*Correspondence: Masako Shomura; Email: rocky36jp@gmail.com; Address: Faculty of Nursing, School of Medicine, Tokai University, Isehara-shi, Kanagawa, Japan.
}

Published by Sciedu Press 
clinical skills, such as communication, assessment, and fundamental medical and nursing procedures. ${ }^{[3]}$

Participatory SPEs have been a part of Japanese nursing education for more than thirty years now, beginning in the 1990s. Even so, they are primarily used only in basic education and research, such as in communication training, interpersonal skills training, and skills testing; participatory SPEs are seldom used in other areas like adult nursing education. ${ }^{[4]}$ Starting in 2002, Tokai University's Adult Nursing Department recruited local residents as Simulated Patients (i.e., to role-play as patients) on the premise that this strategy would ensure the SPEs closely reflect the sociocultural characteristics of the cases that nurses encounter during their clinical training at hospitals. After recruiting the residents, the department developed a participatory SPE program. This training program has proven effective for helping students develop their nursing skills to the point where they can understand patients holistically and provide actual nursing care. ${ }^{[5]}$ Previous research has clarified the process by which lay residents master the task of role-playing a patient ${ }^{[6]}$ and the opinions and attitudes of Simulated Patients. ${ }^{[7]}$ However, the existing research has not adequately examined the significance that participatory SPEs hold for the local residents who act as Simulated Patients.

Therefore, we interviewed the local residents who had participated in the participatory SPE program of Tokai University's Adult Nursing Department. We asked them what they had gained from the program and how they felt about it. We analyzed this interview data to ascertain the roles that instructors need to play, as well as the coordination they need to undertake, in order to develop the SPE program together with local residents.

\section{MethodS}

\subsection{Program overview}

\subsubsection{SPE time}

Two 90-minute sessions $\times 2$ (a total of four sessions).

\subsubsection{Simulated cases}

There are four simulated cases divided into two scenarios. The cases are diabetes, heart failure, leukemia (patient on chemotherapy), and laryngeal cancer (patient on radiation therapy). Each of these cases is tackled by a group. In Scenario 1, the students record the Simulated Patient's condition on the first day, and in Scenario 2, they record the condition a few days after the start of the SPE. To ensure that the cases resemble those that nurses will encounter during their clinical training at hospitals, the students do not receive all the patient information at once. Instead, the information for Scenario 1 is distributed a week before the SPE, and the information for Scenario 2 is distributed midway through the first session of group work.

\subsubsection{Program procedure}

The first session consists of group work. The students learn the basic patient information (such as the condition and the treatment), summarize the information, and prepare themselves for the SPE. The second session consists of group work and an SPE. The students attempt to gather information from the Simulated Patient, assess the Simulated Patient, and then form an overall image of the case. In the third session, the students clarify the nursing problems from the information they gleaned from the second session and formulate a nursing plan. Then, in the fourth session, they apply part of their nursing plan to the SP and evaluate the outcomes.

\subsubsection{The simulated patient's role}

Those who role-play patients for medical and nursing students come from various backgrounds and academic levels. Accordingly, the attributes of the Simulated Patient actors at Tokai University are recorded as follows. Unlike SPE programs in areas of nursing education that focus on training students in diagnosis and treatment, the Adult Nursing Department's SPE program focuses on a Simulated Patient's general health and daily life. First introduced in 2006, the purpose of the program is to train students to implement the nursing process based on a holistic understanding of the patient. Each scenario simulates a patient who is undergoing in-hospital care in a hospital that conducts practical adult nursing training. Accordingly, the Simulated Patient actors are lay residents who live near the hospital and who make contact through the hospital's volunteer association. Before the SPE commences, the department holds a briefing session to convey key information about the students and the patients whom the Simulated Patient actors will portray. After the students have gathered information from the Simulated $\mathrm{Pa}$ tients and implemented their nursing assistance as part of the training, the Simulated Patient actors provide their feedback to each group of students and then to the students as a whole. The program requires around 10 Simulated Patient actors, and almost all the actors continue to perform as Simulated Patients for at least two years.

\subsection{Participants}

The participants in our study were local residents who performed as Simulated Patients in the universities' participatory SPE program between 2006 and 2009, and who agreed to take part in our study.

\subsection{Data collection and data analysis}

The data were obtained on 12 individuals who performed as Simulated Patients in the "chronic care nursing" SPE. 
Table 1 shows the items in the interview guide, that was used by an interviewer to interview each participant. One interviewer was an expert in qualitative research, held a $\mathrm{PhD}$ of nursing, and had no relationship to the faculty who participated in the SPE program. The participants were interviewed separately from August to September 2009. In the interviews, the participants freely discussed what they felt about role-playing a patient and what they gained from the experience. With the participants' permission, we recorded and transcribed entire interviews. We then performed a qualitative inductive analysis on the transcription data following Bernard Berelson's protocol. ${ }^{[8]}$ Berelson's content analysis is characterized by the transformation of communication content into simple phrases; thus, it is most suitable for our research theme. Specifically, for each participant, we carefully read the transcript, partitioned it into sections of meaningful length, abstracted the segmented units, and derived separate codes. Next, we abstracted the separate codes for all participants and extracted sub-categories, categories, and themes. We then plotted a schema showing the relationships between the themes based on the centrality of each theme.

Table 1. Semi-structured interview guide

\begin{tabular}{|cl|}
\hline 1 & $\begin{array}{l}\text { How did you feel about your experience as a Simulated } \\
\text { Patient? Did you notice or discover anything new? }\end{array}$ \\
2 & $\begin{array}{l}\text { Please tell us about the difficulties and hardships you } \\
\text { experienced after agreeing to be a Simulated Patient. }\end{array}$ \\
3 & $\begin{array}{l}\text { In terms of educational goals, do you have any hopes or } \\
\text { expectations toward the students with whom you interacted } \\
\text { during your performance as a Simulated Patient? }\end{array}$ \\
4 & $\begin{array}{l}\text { Do you have any suggestions or hopes regarding the way in } \\
\text { which the nursing students are trained? }\end{array}$
\end{tabular}

To ensure that the results of this analysis were reliable and valid, three researchers analyzed the same data. Then, two researchers who were not involved in the original analysis checked the appropriateness of the analytical procedure, the derived themes, and the plotting of the schema. Moreover, we calculated Scott's $\mathrm{Pi}^{[9]}$ between the three researchers to ensure reliability of our results.

The study was undertaken after receiving authorization from the ethics committee of Tokai University. Participants indicated their consent orally and in writing, and we maintained the participants' privacy throughout the study.

\section{Results}

The participants were in the age range of $60 \mathrm{~s}$ and $70 \mathrm{~s}$, and in addition to those who performed as Simulated Patients for the nursing department, some of the participants had performed as Simulated Patients for the medical department or worked as volunteers in the hospital.

From the 294 statements on the participants' experiences in performing as Simulated Patients, we derived 148 codes, 49 sub-categories, 13 categories, and ultimately 4 themes. Table 2 shows the final 4 themes.

We divided the inter-theme network into quadrants and indicated the connections between each quadrant with arrows, resulting in the construct shown in Figure 1. In the results presented below, themes are shown in inverted commas ("theme"), categories are shown in square brackets ([category]), and participants' statements are bolded and italicized (participant's statement). Looking at the inter-theme network shown in Figure 1, we see that "Self-encouragement and growth" is a central theme, being connected to each of the other three themes. "Self-encouragement and growth" has a mutually improving relationship with "hardships as a Simulated Patient". Additionally, "Self-encouragement and growth" had a mutually encouraging relationship with "efforts to improve the training of Simulated Patient actors and "wishes for nursing students".

Table 2. The experience of local residents who participated in Simulated Patient Exercises (SPE)

\begin{tabular}{ll}
\hline Category (13) & Theme (4) \\
\hline Learning from the experience together with other Simulated Patients and supporting each other & \\
Gained knowledge necessary for patients and reflected on their own behavior & $\begin{array}{l}\text { Self-encouragement and } \\
\text { Pride at contributing to the training of nurses }\end{array}$ \\
$\begin{array}{l}\text { Felt encouraged and inspired } \\
\text { Feeling that students are growing }\end{array}$ & Hardships as a Simulated \\
$\begin{array}{l}\text { A sense of tension and burden as a Simulated Patient } \\
\text { Students did not respond to role-playing efforts sufficiently }\end{array}$ & Patient \\
$\begin{array}{l}\text { Experienced difficulties in, and tried strategies for, giving feedback to students } \\
\text { Find ways to portray a patient accurately }\end{array}$ & Efforts to improve the training \\
Questions about the instructor's role and requests for improvement & Wishes for nursing students \\
Request for human skills of charm and kindness in addition to medical knowledge \\
Morally support the nursing students' diligent efforts
\end{tabular}




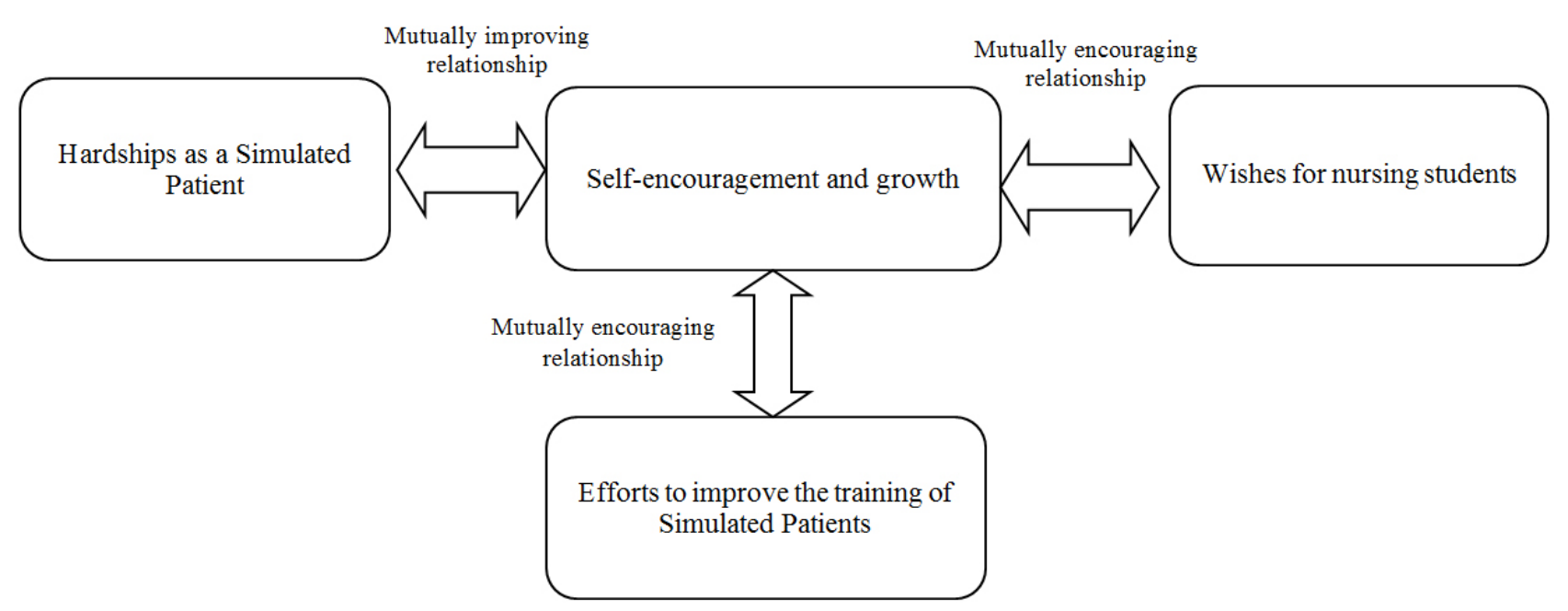

Figure 1. The experience of local residents who participated in simulated patient exercises

\subsection{Self-encouragement and growth}

The residents reported that, by involving themselves with the students as Simulated Patient actors, they obtained [pride at contributing to the training of nurses] and [a sense of seeing the students develop]. At the same time, they [felt encouraged and inspired] by the students' efforts. On the other hand, while attempting to portray a patient as accurately as possible, some residents [gained knowledge necessary for patient and reflected on their own behavior]. The residents stated that by being a useful Simulated Patient for students meant [learning from the experience together with other Simulated Patients and supporting each other], and they felt that this helped them develop as a Simulated Patient. These attitudes are represented in the following statement:

I felt I was performing a service to the society. By performing as a Simulated Patient, I strongly felt that I was helping the students, and this in turn reflects back to me.

\subsection{Hardships as a simulated patient}

The participants felt a sense of responsibility in involving themselves in the students' training. Accordingly, they felt [a sense of tension and burden as a Simulated Patient]. The residents made conscientious efforts to role-play each patient while harboring a sense of burden, but they felt that the [students did not respond to role-playing efforts sufficiently]. The participants therefore reported that they wanted to spur the students on. These attitudes are represented in the following statement:

I would answer the students' questions, and then the students would come back with a nursing plan. I'm not sure whether this is good or bad, but I felt that I could have spoken to them in a way that would have been more assistive for the students to prepare their nursing plans. I could have been more emphatic and insisted a little more firmly, perhaps. To be honest, the students' responses were not what I had expected. I mentioned a certain symptom, but evidently the message did not get through to them. Therefore, I felt that I could have performed better, to make it easier for the students to prepare their plans.

\subsection{Efforts to improve the training of simulated patients}

As an example of "efforts to improve the training of Simulated Patients," the participants mentioned how they took great pains to [find ways to portray a patient accurately]. They also reported taking great pains to fulfill the important Simulated Patient duty of providing feedback to students; in other words, they [experienced difficulties in, and tried out strategies for, feedback to students]. In relation to these efforts, the participants mentioned that the instructor should give more suggestions and directions on how to role-play as a Simulated Patient; in other words, they cited [questions about the instructor's role and requests for improvement]. These attitudes are represented in the following statement:

I experienced it a number of times, but I forget it all soon after it. I must apologize. I would read the scenario thoroughly beforehand, but I'd become too nervous thinking about the students.

At the risk of seeming impudent, compared to medical students who focus on diagnosis, when it comes to nursing students, it is unclear what image one should draw of the patient to portray them. There should be clearer directions on how to act as a Simulated Patient. 


\subsection{Wishes for nursing students}

The participants' "wishes for nursing students" included [requests for human skills of charm and kindness in addition to medical knowledge] and [expectations that the students will become strong and kind nurses]. The participants noted some differences between individual students and between the groups of students, and they felt that some of them needed to study more. However, they ultimately wanted to [morally support the nursing students' diligent efforts]. These attitudes are represented in the following statement:

Ultimately, I want to morally support the students. You can see such eagerness in these women's eyes. From here on, they will encounter various hardships, but when you see these women and men, you get a keen sense of how they will overcome these challenges and forge a bright future. I want to wish them the very best of luck and I expect them to excel as nurses.

\subsection{Scott's Pi}

The concordance rate among the three researchers from categories to themes had a Scott's Pi rating of 92.6\%. This shows that these results are statistically reliable.

\section{Discussion}

When we listened to the experiences of local residents who portrayed as patients in Simulated Patient Exercises, we heard many statements about the hardships they faced as a Simulated Patient, including their nervousness and the strain of learning their part.

On the other hand, we also heard many positive statements about how the residents felt encouraged, and how they achieved a sense of growth, through their experience as a Simulated Patient. For example, in serving as Simulated Patients, the residents gained a sense of pride at how they were helping to train nursing students who will in the future help them and their family members, and they felt inspired by the students' earnestness and their cordial learning attitudes, as well as by their camaraderie with fellow Simulated Patients. These positive statements illustrate the value in local residents participating in case simulations as Simulated Patients, and they explain why the residents continued to participate. This understanding is corroborated by Yoshikawa et al., ${ }^{[10]}$ who reported that participants continue to serve as Simulated Patients when their participation brings them positive outcomes and helps them form interpersonal connections.

The interview data highlighted some areas that instructors need to improve to develop a better system of practical nurse training together with local residents. For example, the participants want the instructors to offer backup in terms of

Published by Sciedu Press "wishes for nursing students" and "efforts to improve the training of Simulated Patients." They also wanted instructors to refine the scenarios, emphasize the key performance points, and to give clearer directions on how to role-play the patient. Such feedback can be incorporated into the future training of Simulated Patients. According to Yoshikawa et al., ${ }^{[10]}$ when it comes to the instructor's role in encouraging the person to continue as a Simulated Patient, it is essential that the instructor is a skilled facilitator and reviews past performances. The findings of our study, as well as those of other studies, suggest that to make a participatory SPE program (in which local residents perform as Simulated $\mathrm{Pa}$ tients) even more useful for nursing students, it is essential to improve instructors' facilitation skills and to set aside time for review sessions after an SPE is finished, as opposed to only arranging a session beforehand. We believe it is vital to introduce participatory SPEs into classes from the first year onward, ${ }^{[11]}$ and to ensure close cooperation among a multi-disciplinary instructor team to make it easier for the Simulated Patient actors to get a sense of the students' growth. Recent research introduced the concept of sequential simulation education, which depends on the patient's real experiences and contributes to the development of integrative care competencies. Our Simulated Patients constituted a relatively healthy group, and faculty members asked them to consider avoiding the addition of the symptoms of their actual conditions in their simulations. This was done in order to facilitate the diagnosis skills of nursing students. However, students could learn and have positive experiences through sequential simulation education, in which Simulated Patients would integrate their own personal health histories and experiences into their simulations. ${ }^{[12,13]}$ In future SPEs, we should consider the local residents' experiences as patients because they may strengthen the performance, and therefore the educational value, of each Simulated Patient.

The limitation of this study is that it was conducted in a single university with a relatively small number of participants. Future study should include participants drawn from multiple centers worldwide, thus allowing for comparison of the Simulated Patient and SPE phenomena across national, regional, social, and cultural distinctions. Moreover, future study should also assemble a global team of researchers, which would help to broaden the research perspective.

\section{Conclusion}

In conclusion, we derived four themes describing the residents' experiences: "Self-encouragement and growth", "hardships as a Simulated Patient", "efforts to improve the training of Simulated Patients" and "wishes for nursing students". Many of the statements described hardships that 
residents faced as Simulated Patients, including their nervousness and the burden of learning their role. On the other hand, we also heard many positive statements about how the residents felt encouraged by and attained personal growth through the experience. For example, in serving as Simulated Patients, the residents were encouraged by a sense of pride at how they were helping to train nursing students who would in the future help them and their family members, and they felt inspired by the students' earnestness and their cordial learning attitudes, as well as the camaraderie among fellow Simulated Patients. These positive statements illustrate the value of local residents participating in the program, and they explain why the residents continued to participate.

\section{ACKNOWLEDGEMENTS}

We would like to thank all participants who contributed to our nursing education and this study. The authors declare that they have no competing interests. This study was supported by funding from School of Health Sciences Tokai University. We would like to thank Editage (www.editage.jp) for English language editing.

\section{CONFlicts OF INTEREST Disclosure}

The authors declare that there is no conflict of interest.

\section{REFERENCES}

[1] Shimizu Y, Yokoi Y, Toyoda S, et al. The characteristics of a study about SP (Simulated Patient/Standardized Patient) in nursing education. J Jpn Health Sci. 2008; 10: 215-223. https ://doi .org/10 .24531/jhsaiih.10.4_215

[2] May W, Park JH, Lee JP. A ten-year review of the literature on the use of standardized patients in teaching and learning: 1996-2005. Med Teach. 2009; 31: 487-492. PMid:19811163 https://doi.or $\mathrm{g} / 10.1080 / 01421590802530898$

[3] Cook DA, Hamstra SJ, Brydges R, et al. Comparative effectiveness of instructional design features in simulation-based education: systematic review and meta-analysis. Med Teach. 2013; 35: e86798. PMid:22938677 https ://doi .org/10.3109/0142159X . 201 2.714886

[4] Honda T, Uemura T. Literature Review on application of simulated patients in basic nursing education -Focused on its characteristic, effects and challenges. Japanese Red Cross Kyushu International College of Nursing Intramural Research Report. 2009; 7: 67-77. https://doi.org/10.15019/00000259

[5] MacLean S, Kelly M, Geddes F, et al. Use of simulated patients to develop communication skills in nursing education: An integrative review. Nurse Educ Today. 2017; 48: 90-98. PMid:27741440 https://doi.org/10.1016/j.nedt.2016.09.018

[6] MacLean S, Geddes F, Kelly M, et al. Simulated patient training: Using inter-rater reliability to evaluate simulated patient consistency in nursing education. Nurse Educ Today. 2018; 62: 85-90.
PMid:29306751 https://doi.org/10.1016/j.nedt.2017.12 .024

[7] Thomson FC, MacKenzie RK, Anderson M, et al. Incorporating patient partner scores into high stakes assessment: an observational study into opinions and attitudes. BMC Med Educ. 2017; 17: 214221. PMid:29141624 https://doi.org/10.1186/s12909-017 -1063-4.

[8] Berelson B. Content analysis in communication research, New York: The Free Press; 1952.

[9] Scott W. Reliability of content analysis: The case of nominal scale coding. Public Opinion Quarterly. 1955; 19(3): 321-325. https://doi.org/10.1086/266577

[10] Yoshikawa Y, Watanabe Y, Yamamoto K, et al. Considerations in providing the continued support to simulated patients in nursing education. SCU J Design Nurs. 2016; 10: 49-57. https ://doi/10.1 5025/00000125

[11] Au ML, Lo MS, Cheong W, et al. Nursing student's perception of high-fidelity simulation activity instead of clinical placement: A qualitative study. Nurse Educ Today. 2016; 39: 16-21. PMid:27006029 https://doi.org/10.1016/j.nedt.2016.01.015

[12] Weldon SM, Ralhan S, Paice L, et al. Sequential simulation of a patients journey. THE CLINICAL TEACHER. 2017; 14: 90-94. PMid:27329830 https://doi.org/10.1111/tct. 12549

[13] Powell P, Sorefan Z, Hamilton S, et al. Exploring the potential of sequential simulation. THE CLINICAL TEACHER. 2016; 13: 112-118. PMid:26119637 https://doi.org/10.1111/tct.12391 